\title{
Physiological basis and molecular mechanism of cold resistance enhanced by molybdenum application in winter wheat (Abstract)
}

\author{
Xuecheng Sun \\ College of Resource and Environment, Huazhong Agricultural University, Wuhan, China \\ Corresponding author: sxccn@mail.hzau.edu.cn
}

\begin{abstract}
Molybdenum (Mo) is an essential element for plant growth and development. Mo itself seems to gain biological function until it is complexed by Mo-containing enzymes. Mo application increase the yield of wheat by $20-30 \%$ in Mo-deficiency areas and enhanced the cold-resistance of winter wheat. In order to improve our understanding of the molecular mechanisms of cold resistance arising from application of Mo in winter wheat, effects of molybdenum on Mo-enzymes, hormones, antioxidative enzymes, expression of coldresponsive (COR) genes and quantitative proteomics, composition of thylakoids and photosynthetic parameters were investigated. The results showed Mo increased the Mocontaining enzymes such as NR, AO and XDH. Further evidence showed that Mo might regulate the expression of ABA-dependent $\mathrm{COR}$ genes through the pathway: $\mathrm{Mo} \rightarrow \mathrm{AO} \rightarrow \mathrm{ABA} \rightarrow \mathrm{bZIP} \rightarrow \mathrm{ABA}-d e p e n d e n t \mathrm{COR}$ genes in winter wheat. In addition, most of differential proteins were located in membrane of thylakoids, and their functions were closely related to light reactions and dark reactions of photosynthesis. The results of COR gene expression and differential proteins were also supported by the results concerning composition of thylakoids and photosynthetic parameters. So a mechanism was initially put forward: molybdenum regulated the gene expression via Mo-enzymes, and then successively affected the protein expression, metabolic processes, physiological functions such as enhancing the photosynthesis, andcold resistance in winter wheat.
\end{abstract}

Keywords: Cold resistance, molybdenum, winter wheat. 
